\title{
Pemanfaatan E-Commerce untuk Optimalisasi Penjualan dan Pemasaran Produk Shopsock Berbasis Web
}

\author{
Elisa Mei Sintiasari ${ }^{\mathrm{a}, 1^{*}}$, Donna Setiawati ${ }^{\mathrm{a}, 2^{*}}$, Wisnu Sanjaya ${ }^{\mathrm{a}, 3}$ \\ ${ }^{a}$ Fakultas Ilmu Komputer, Universitas Boyolali, J1. Pandanaran No.405, Boyolali 57315, Indonesia \\ ${ }^{1}$ elisamei45@gmail.com; ${ }^{2}$ donna.setiawati@gmail.com; ${ }^{3}$ wisnuksl@ gmail.com \\ * Koresponsendi penulis
}

\section{ARTICLE INFO}

Article history

Menerima 11 September 2020

Revisi 23 Juli 2021

Diterima 28 Juli 2021

Kata Kunci

E-Commerce

Website

Pemasaran

Shopsock

\section{ABSTRACT}

Shopsock is one type of business in the field of shoe sales, so far the sale of shopsock products has been carried out by interacting with direct consumers and the marketing is not optimal. To optimize product sales and marketing, in this study an online sales website (e-commerce) was built to display information on products sold in shopsock stores and customers can easily make purchases. This website was built using the waterfall method, object modeling using UML, open source programming tools based on PHP, MySQL database and the result achieved is an e-commerce website to expand market prey for promotion and make it easier for consumers to buy shopsock products.

This is an open access article under the CC-BY-SA 4.0 license.

\section{Pendahuluan}

Perkembangan teknologi saat ini berdampak positif bagi perusahaan yang bergerak dibidang industri, penjualan maupun jasa. Teknologi yang berkembang membawa perubahan yang cukup nyata yaitu proses transformasi bisnis kearah digitalisasi. Digitalisasi berarti mengubah sesuatu menjadi digital atau memanfaatkan teknologi untuk memangkas biaya operasional, tanpa mengorbankan kualitas produk/pelayanan atau bahkan harus meningkatkannya. Namun digitalisasi bisnis bukan semata-mata menggunakan teknologi untuk menggantikan tenaga manusia, tapi lebih kepada bagaimana sebuah perusahaan dapat menciptakan sistem otomatis dan terintegrasi satu dengan yang lain [1]. Digitisasi penjualan memberikan sejumlah kelebihan operasional seperti pemrosesan data pemesanan menjadi lebih mudah ditelusuri, sistem persediaan dan pembayaran lebih akurat, dapat membangun hubungan yang baik dengan pelanggan Sistem informasi penjualan berbasis web secara signifikan dapat memperluas pangsa pasar dengan proses bisnis yang lebih dinamis dan interaktif serta memiliki pola diferensiasi yang jelas untuk semua segmen masyarakat [2].

Pemerintah melalui Menteri Komunikasi dan Informatika (Menkominfo) juga mendukung program digitalisasi UMKM, karena UMKM sebagai penyumbang 61,07\% PDB (Produk Domestik Bruto) Indonesia. Digitalisasi UMKM perlu didukung oleh dua ekosistem, yakni ekosistem e-Commerce dan ekosistem UMKM. Dalam ekosistem e-Commerce, Menkominfo menyatakan telah menyiapkan kebijakan pelindungan data pribadi serta logistik untuk mendukung transaksi elektronik [3]. Saat ini banyak toko yang memanfaatkan metode ecommerce atau biasa disebut toko online. Pelanggan tidak harus datang langsung ke toko untuk membeli, namun saat ini dengan kemajuan teknologi e-commerce dapat melihat produk yang 
ditawarkan dan melakukan transaksi penjualan hanya melalui komputer atau smartphone. Salah satu contoh toko yang sudah menggunakan ecommerce adalah toko pakaian A\&S di Tangerang Banten [4].

Shopsock merupakan salah satu jenis usaha startup yang menjual produk sepatu beralamat di Jl. Teratai No. 2 Boyolali. Saat ini proses penjualan dan pemasarannya terbatas hanya di toko saja. Shopsock ingin mengembangkan usahanya agar lebih luas pangsa pasarnya, maka perlu melakukan perubahan sistem yang selama ini berjalan kearah digitalisasi. Shopsock memerlukan sarana pemasaran yang luas dan penjualan yang mudah dan aman tanpa batasan waktu dan tempat. Sistem informasi penjualan berbasis web memungkinkan pembeli juga dapat mengecek status pemesanan melalui halaman tracking order, sehingga pembeli dapat mengetahui posisi pemesanannya apakah sudah dipacking, ataupun sudah proses pengiriman [5]. Selain itu, adanya penjualan berbasis web maka penjual dapat mengembangkan usahanya dengan memberikan segala promosi yang mudah dilihat oleh orang banyak [6].

Dalam pembuatan e-commerce agar dapat mendorong penjualan bisnis online maka salah satu fitur yang perlu disediakan adalah fitur wishlist. fitur wishlist adalah sebuah fitur yang dapat menyimpan keranjang belanja dimana terdapat kondisi seorang pelanggan berminat pada produk yang dipilih namun pelanggan tersebut belum berminat untuk membelinya saat ini [7]. Berdasarkan penjelasan diatas, permasalahan yang terjadi pada toko ini dapat dirumuskan yaitu bagaimana membangun media informasi bagi konsumen berbasis website dan bagaimana memanfaatkan e-commerce untuk penjualan dan pemasaran. Aplikasi yang dibuat untuk pembayarannya menggunakan transfer bank atau bayar ditempat serta untuk pesan antar melalui ekspedisi dengan biaya pengirimannya ditanggung oleh pembeli. Urgensi tujuan penelitian ini adalah merancang, mengimplementasikan aplikasi e-commerce berbasis website untuk memudahkan promosi barang yang dijual serta transaksi pembelian.

\section{Metode Penelitian}

Lokasi penelitian di toko ShopSock yang beralamat di Jl.Teratai No.2 Kelurahan Pulisen Kecamatan Boyolali, Kabupaten Boyolali. Tahapan dalam merancang sistem adalah pertama, melakukan analisa kebutuhan. Pada tahap ini melakukan wawancara dengan Bapak Saputro Nugroho sebagai pemilik toko untuk mendapatkan informasi terkait produk yang dijual yang meliputi harga, spesifikasi, dokumentasi produk serta data penjualan dan proses transaksi penjualan. Pengamatan secara langsung atau observasi dilakukan untuk mengetahui pendataan yang dilakukan serta proses penjualan yang dilakukan oleh toko ini. Studi literatur atau penelusuran pustaka seperti jurnal, buku dan informasi di internet diperlukan untuk menambah informasi terkait pembuatan aplikasi ini.

Tahap kedua yaitu melakukan analisis berdasarkan hasil mengumpulkan data dari tahap analisa kebutuhan sebelumnya. Hasil wawancara menyatakan bahwa 1). Metode pemasaran masih kurang maksimal yaitu hanya dengan media sosial yang terbatas seperti whatsapp, twiter, instagram tapi menurut pemilik toko jangkauan pasarnya kurang luas. 2) Belum adanya website untuk media promosi dan penjualan sehingga pembeli harus datang ke toko untuk membeli. 3). Pemasaran produk hanya menggunakan brosur/flyer. Berdasarkan hasil analisis diatas, maka analisis kebutuhan sistemnya yaitu sistem akan dapat memberikan informasi yang spesifik tentang barangbarang yang dijual pada toko ini, sistem dapat menampilkan update stok produk yang baru, sistem dapat menangani proses pemesanan produk dengan mudah dan cepat.

Tahap ketiga melakukan desain atau perancangan sistem sebelum melakukan coding. Perancangan menggunakan use case diagram, activity diagram dan sequence diagram. Use case menggambarkan tentang bagaimana seorang pengguna akhir berinteraksi dengan sistem [8]. Pada Fig. 1 terdapat 2 (dua) aktor yaitu Admin dan User. Admin dapat melakukan beberapa proses seperti: melihat produk, tambah produk, ubah produk, login akun, mengubah data pelanggan. Sedangkan user dapat melakukan proses lihat produk, tambah produk ke keranjang, ubah produk, login akun ubah data pelanggan, lihat belanja dan melakukan wishlist barang. Fig. 2 merupakan sebuah diagram aktivitas (activity diagram) untuk melengkapi use case yang telah dibuat sebelumnya. Aktivitas dimulai dari Admin mengolah data produk sepatu dan dimasukkan kedalam sistem. Pelanggan membeli produk dan dimasukkan ke keranjang belanja. Selanjutnya sistem akan 
melakukan proses transaksi dan informasi transaksi dikelola oleh admin untuk selanjutnya admin mengirimkan pesanan dan pelanggan menerima pesanan.

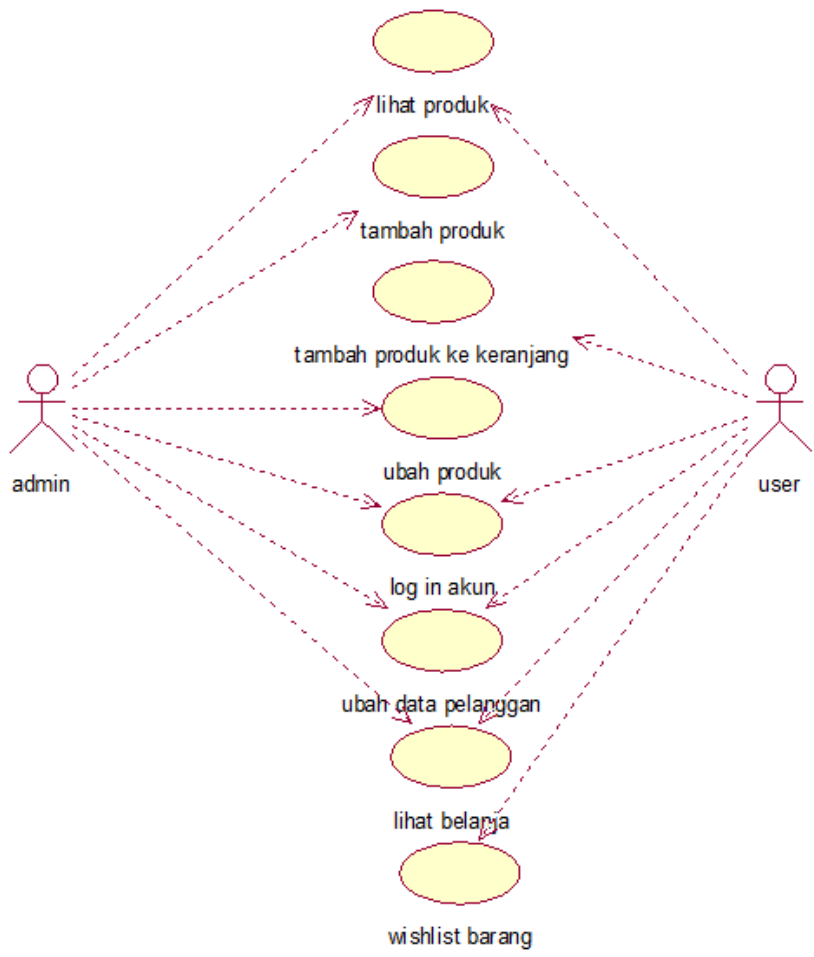

Fig. 1. Usecase Diagram

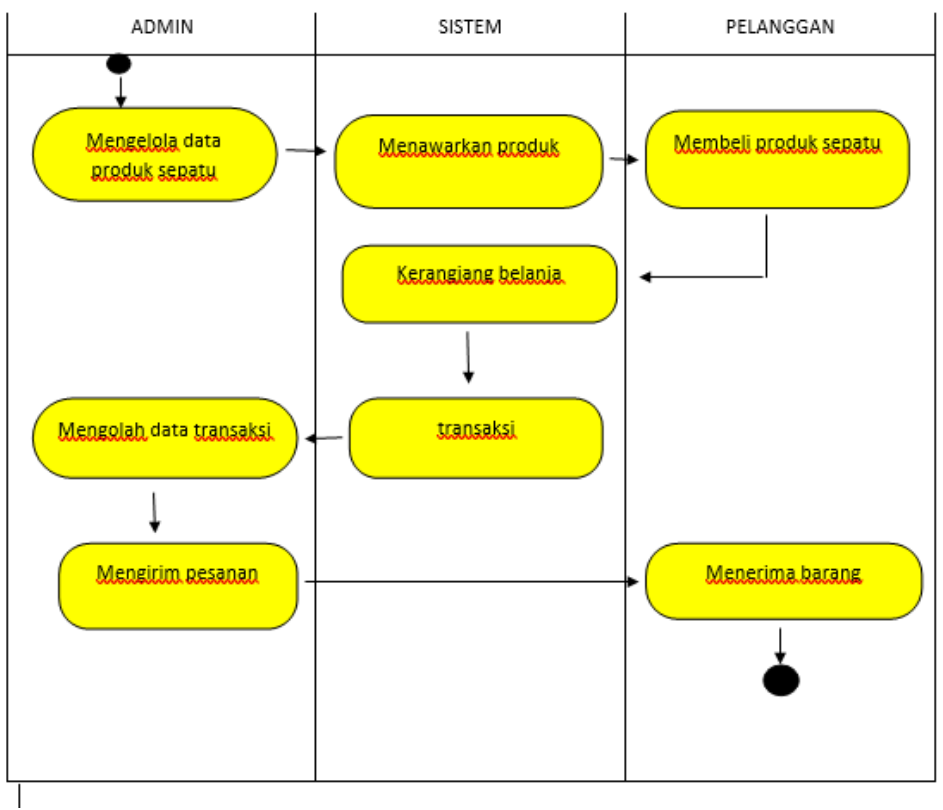

Fig. 2. Activity Diagram

Sequence diagram menggambarkan interaksi antar objek yang berada didalam dan disekitar sistem. Sequence diagram digunakan untuk menggambarkan skenario atau rangkaian langkah-langkah yang dilakukan sebagai respons dari sebuah event untuk 
menghasilkan output tertentu. Fig. 3 merupakan Sequence diagram Pelanggan, sedangkan Fig. 4 merupakan Sequence diagram Admin.

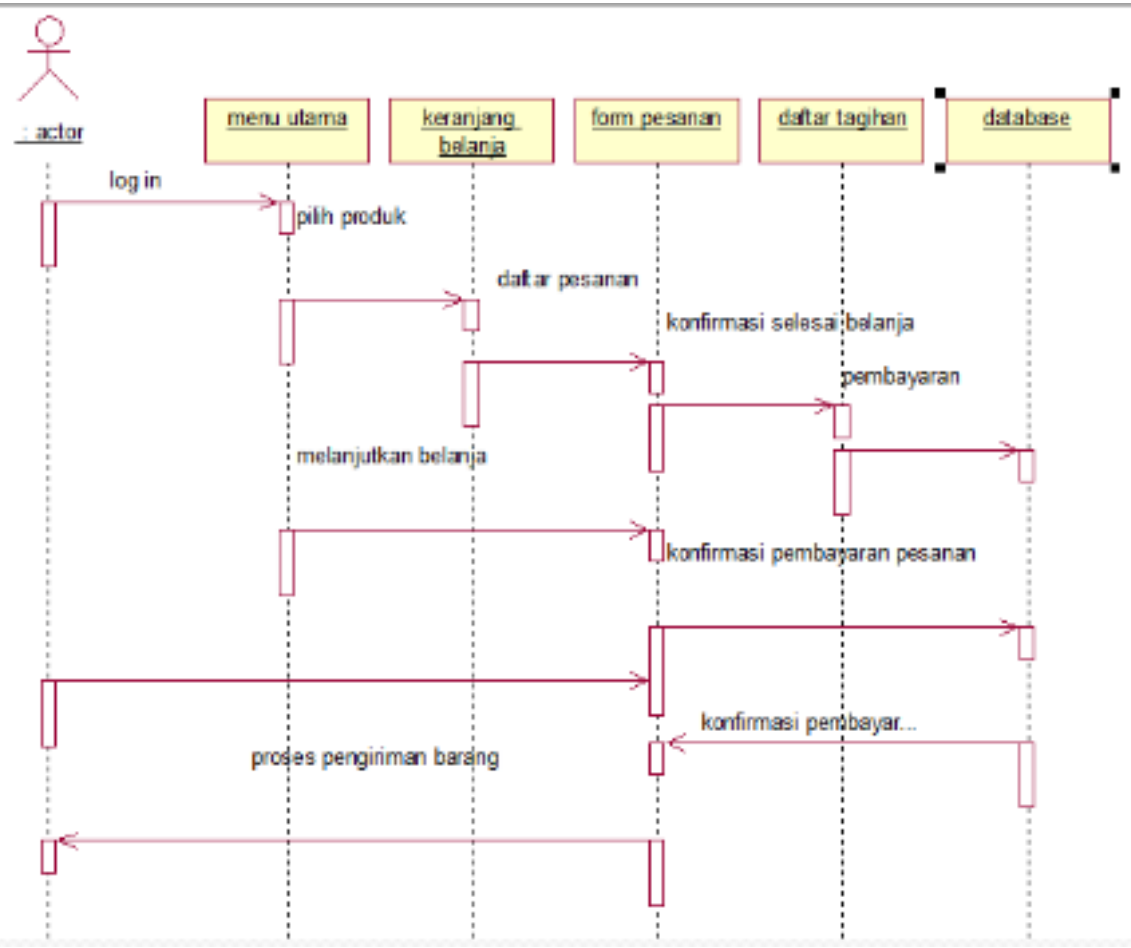

Fig. 3. Sequence Diagram Pelanggan

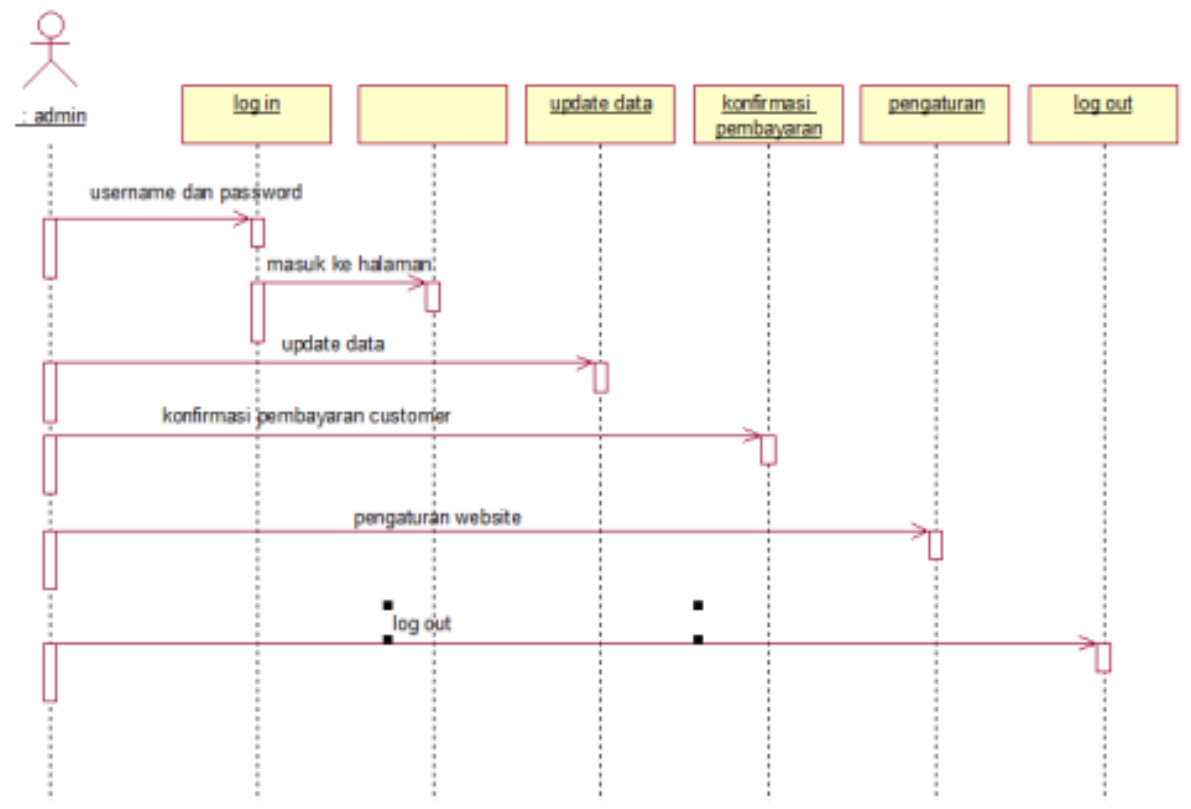

Fig. 4. Sequence Diagram Admin

\section{Hasil dan Pembahasan}

Dalam tahapan pengembangan sistem setelah melakukan desain atau perancangan maka selanjutnya tahap implementasi dengan membuat coding. Hasil implementasi merupakan penerapan yang diperoleh dari analisa kebutuhan sampai dengan konstruksi untuk mewujudkan sistem e-commerce yang diusulkan.

Pada saat website dibuka pertama kali maka yang akan muncul halaman utama seperti Fig. 5. Halaman utama terdapat menu, logo, dan slider gambar produk yang dijual atau ditawarkan, fitur 
login akun digunakan sebagai media mendaftar anggota/member yang akan melakukan tranksaksi pembelian, kolom untuk pencarian barang dan di sebelah kanan terdapat kontak yang bisa dihubungi oleh pelanggan. Pelanggan yang akan melakukan transaksi pembelian maka diharuskan mendaftar atau login terlebih dahulu. Fig. 6 merupakan halaman meminta pengunjung untuk memasukan biodata lengkap untuk mendaftar sebagai pelanggan diantaranya username dan password yang akan digunakan untuk login website, serta nama lengkap, alamat lengkap, nomor hp, dan alamat email.

Pelanggan sebelum memutuskan untuk membeli dapat melihat spesifikasi produknya terlebih dahulu seperti pada Fig. 7. Halaman ini menampilkan produk yang dijual / ditawarkan oleh Shopsock dengan disertai nama, harga, spesifikasi barang yang dijual dan jumlah stock yang tersedia. Pelanggan selain dapat langsung melakukan transaksi pembelian, dalam website ini juga terdapat fitur wishlist. Fig. 8 merupakan fitur wishlist yang dapat digunakan oleh pelanggan jika sudah memilih produk yang diminati namun belum melakukan pembelian saat ini.

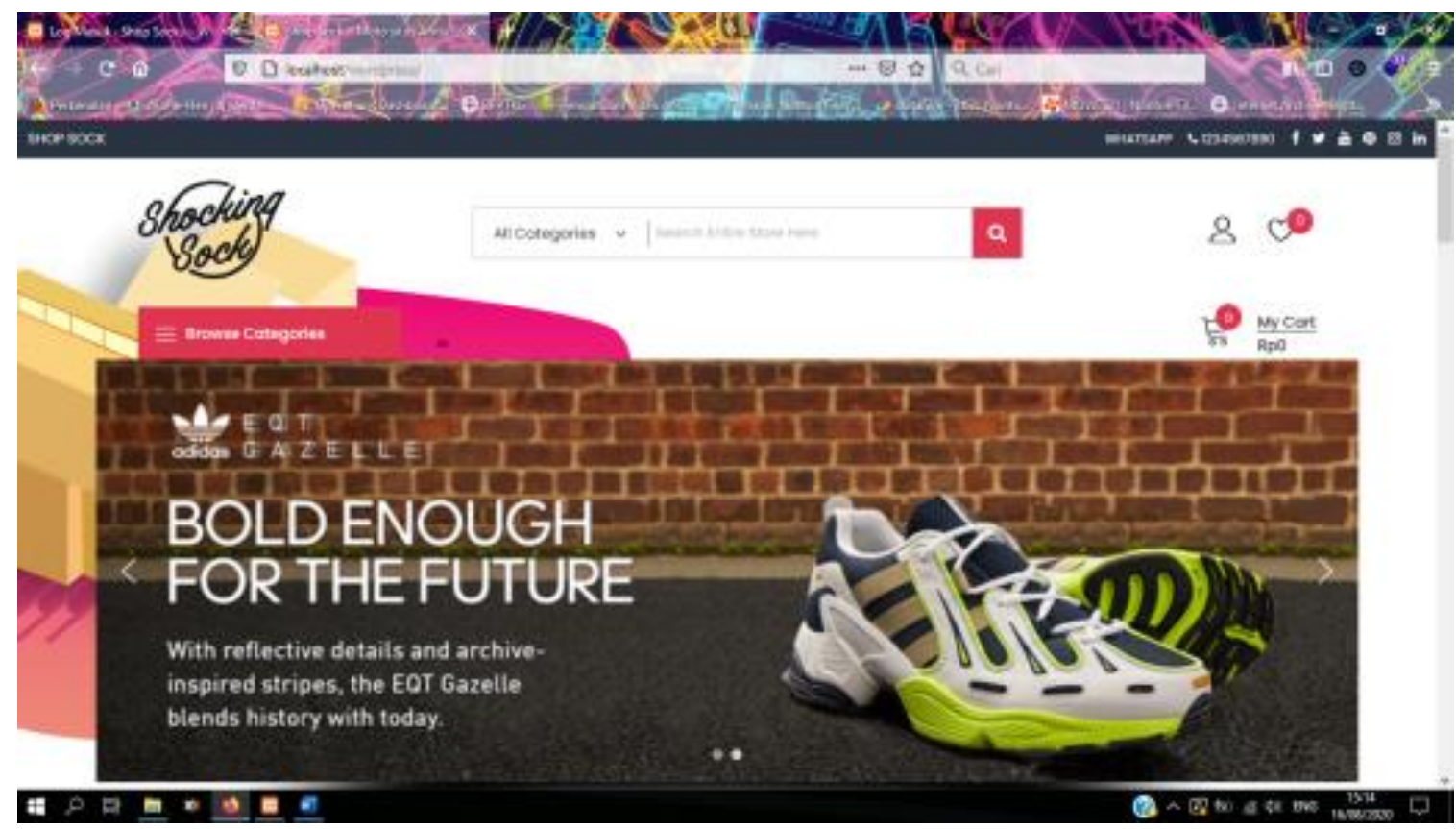

Fig. 5. Tampilan Halaman Utama Website
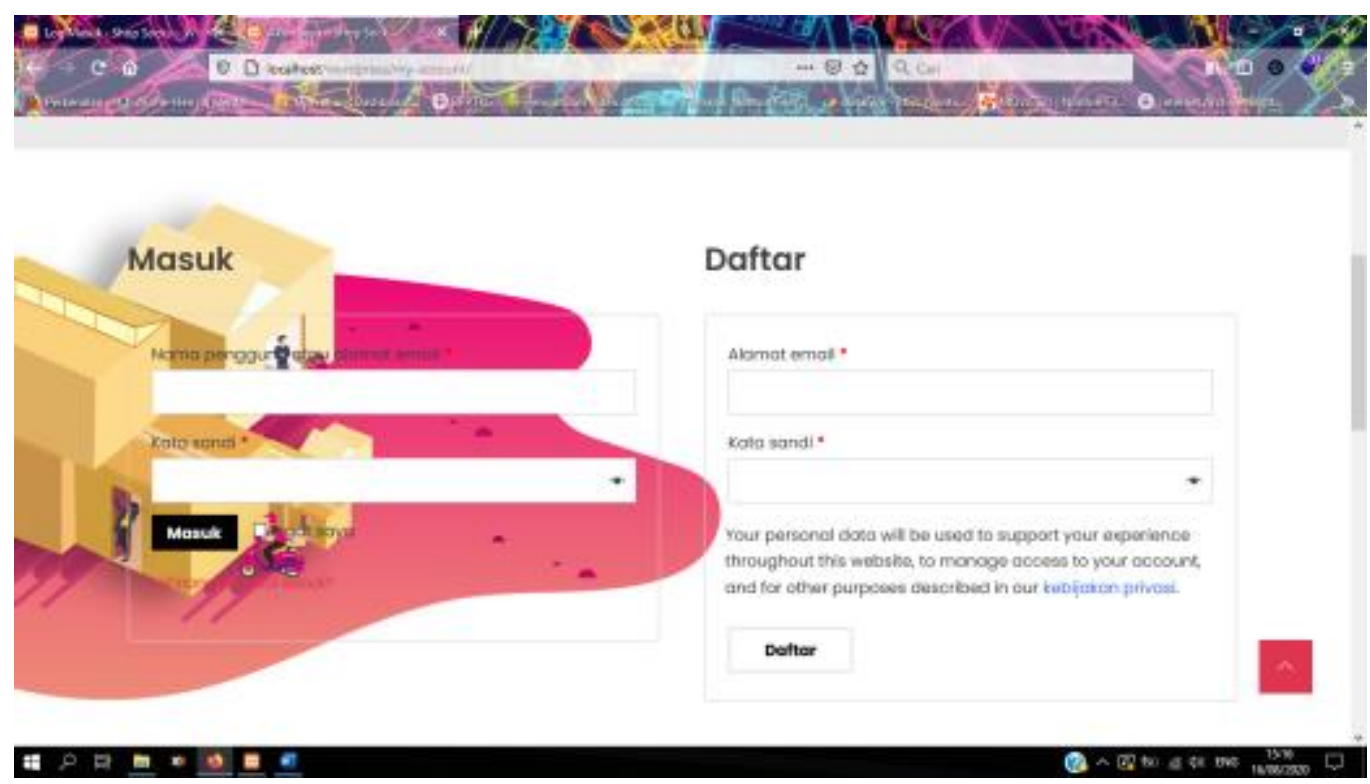

Fig. 6. Tampilan Pendaftaran Pelanggan

Elisa Mei Sintiasari et.al (Pemanfaatan E-Commerce Untuk Optimalisasi Penjualan Dan Pemasaran Produk Shopsock Berbasis Web) 
Pelanggan yang sudah memilih sepatu yang diinginkan dapat memasukkan kedalam keranjang belanja. Tampilan keranjang belanja seperti pada Fig. 9 yang menampilkan produk yang dibeli, harga, jumlah dan total yang harus dibayar oleh pelanggan. Langkah selanjutnya pelanggan melakukan pembayaran dan konfirmasi pembayaran. Pembayaran dapat dilakukan secara transfer ke bank yang sudah ditentukan oleh toko atau bayar ditempat. Pesanan akan diproses jika konfirmasi pembayaran telah dilakukan.

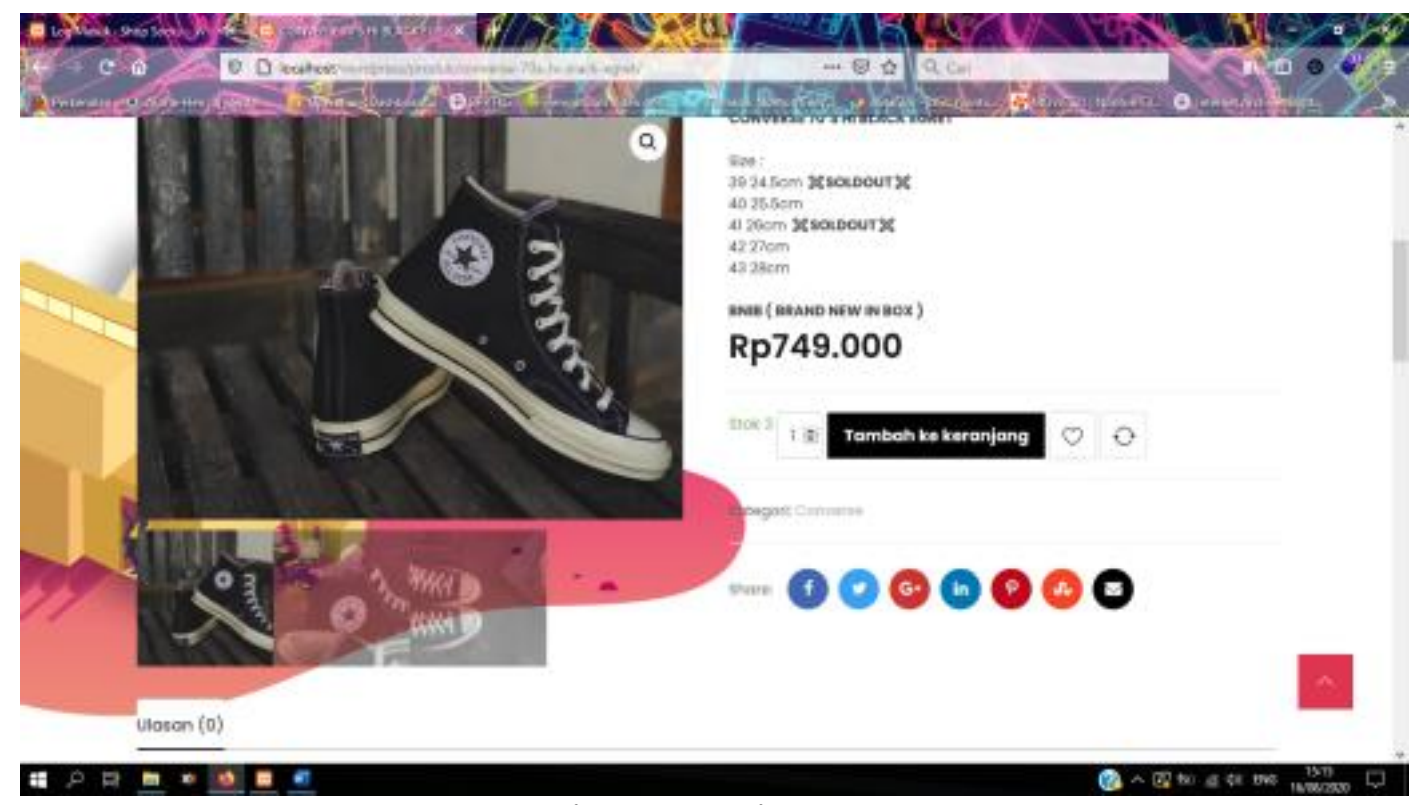

Fig. 7. Tampilan Produk
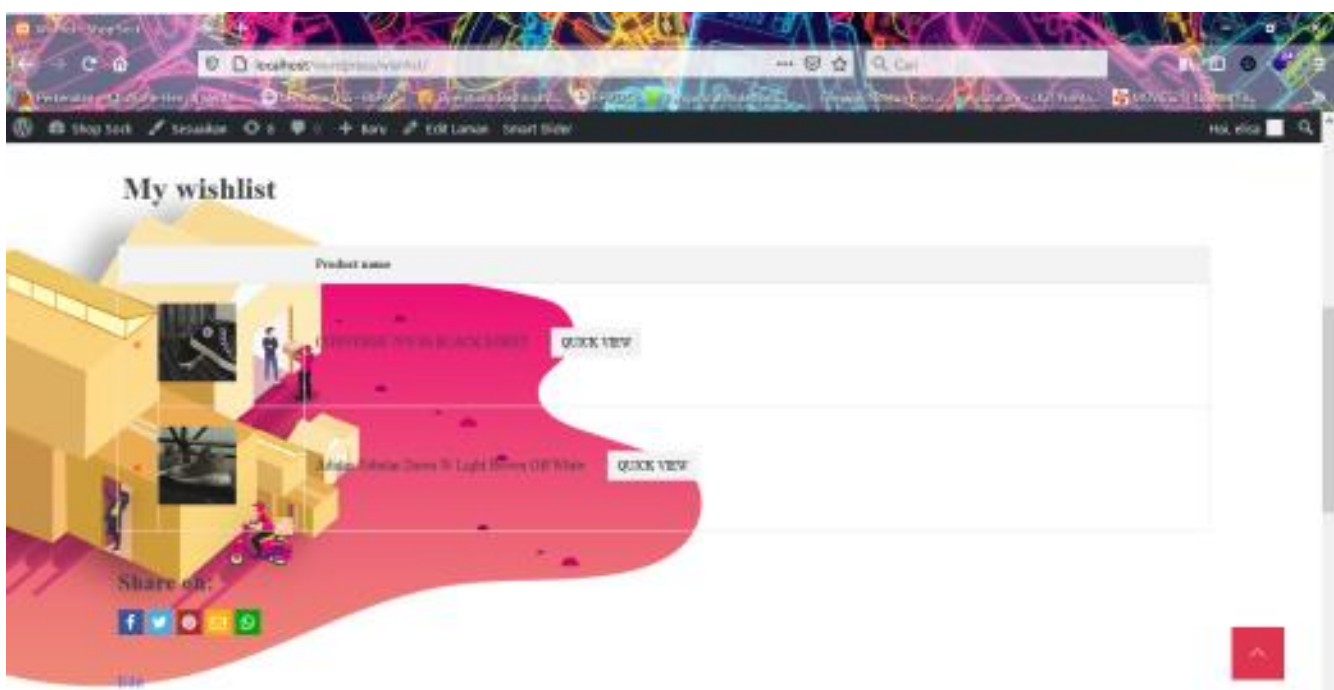

Fig. 8. Tampilan WishList 


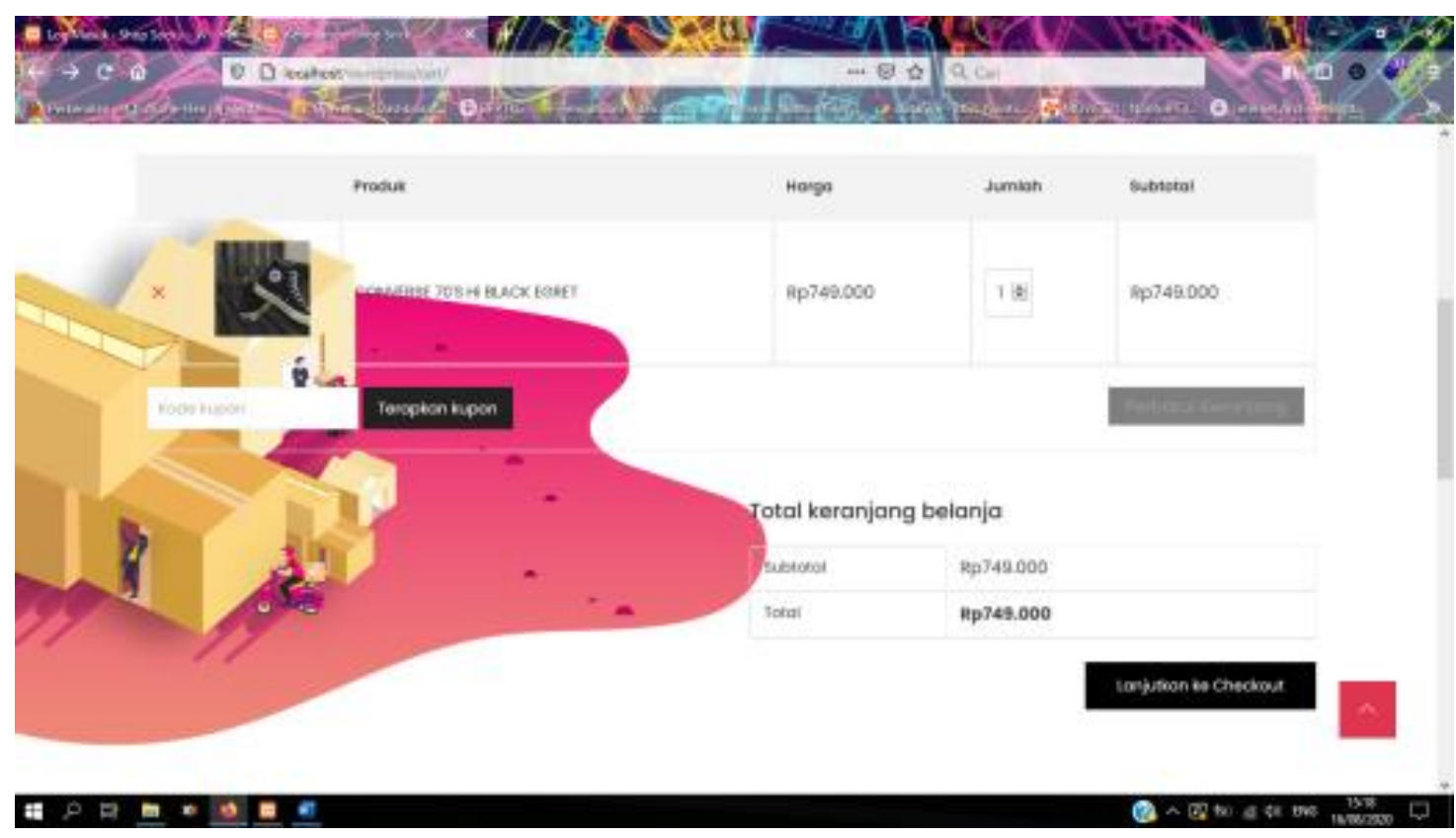

Fig. 9. Tampilan Keranjang Belanja

Website ini selain terdapat menu untuk pelanggan juga ada menu untuk admin. Admin bertugas mengelola data pelangan, data produk serta data pesanan. Pelanggan setelah melakukan pembelian maka data pesanan akan muncul pada daftar pesanan yang dapat dilihat oleh admin. Tampilan halaman daftar pesanan seperti pada Fig. 10, terlihat semua pelanggan yang melakukan pemesanan dapat terlihat pada halaman tersebut. Begitu pula jika pembeli sudah melakukan transaksi dan sudah melakukan konfirmasi pembayaran maka admin dapat mengkonfirmasi dan barang akan diproses. Tampilan halaman konfirmasi oleh admin seperti pada Fig. 11.

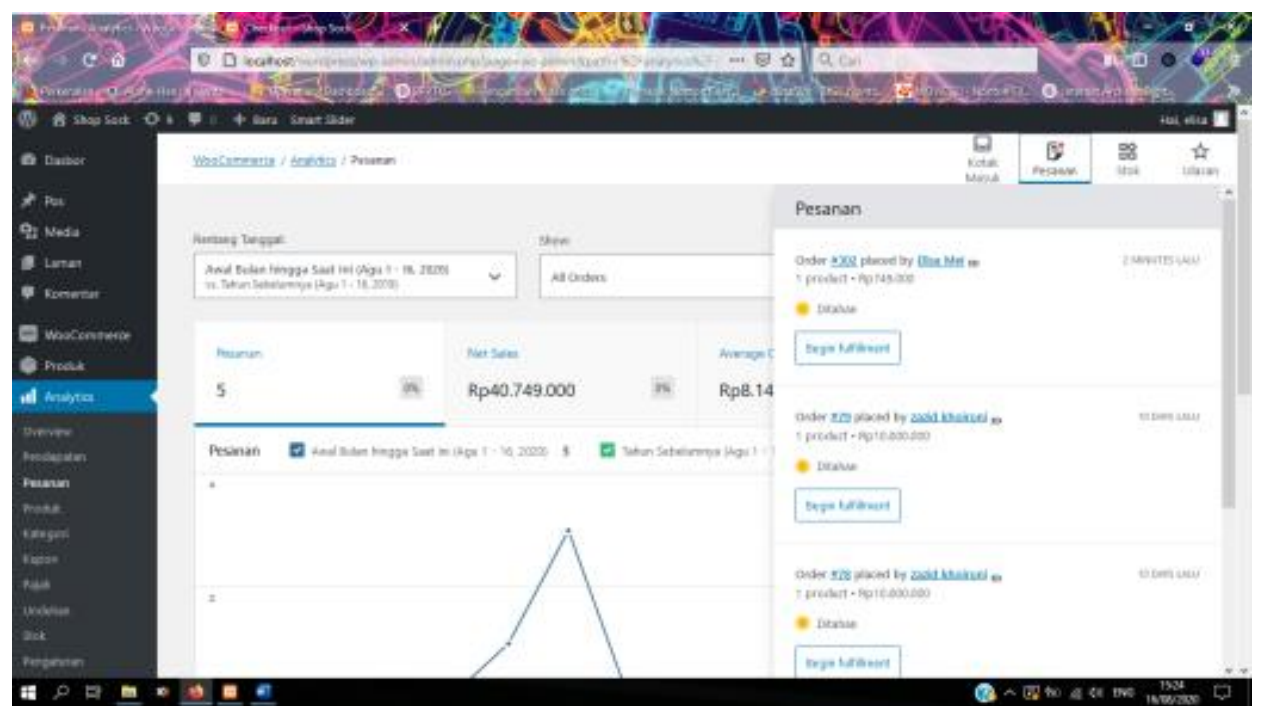

Fig. 10. Tampilan Daftar Pesanan 


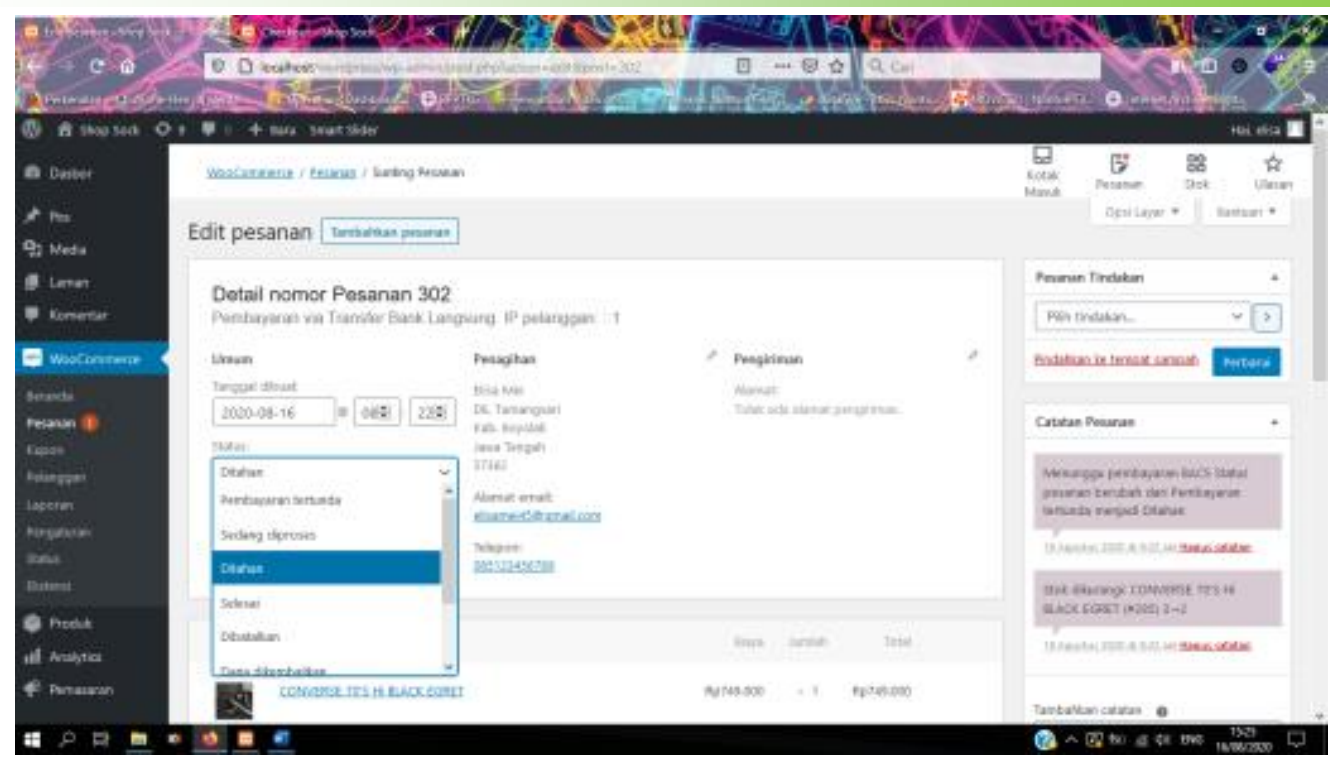

Fig. 11. Tampilan Daftar Konfirmasi

Berdasarkan tujuan penelitian yang telah ditetapkan sebelumnya yaitu hasil aplikasi e-commerce berbasis website ini diharapkan dapat memudahkan promosi barang yang dijual serta transaksi pembelian, maka penjelasannya sebagai berikut:

Saat ini promosi dapat dilakukan dengan mengelola data produk sepatu dan proses mengupdate lebih cepat, sehingga pelanggan dimana saja berada dapat langsung melihat produk yang ditawarkan. Pelanggan dapat mengakses informasi tersebut tanpa terhalang oleh waktu, baik pagi, siang maupun malam. Pada sistem offline, pelanggan hanya dapat melihat produk saat toko dibuka pada jam kerja yang sudah ditentukan. Penelitian ini mendukung penelitian sebelumnya yang juga berhasil mengimplementasikan e-commerce pada toko sepatu Kinya Store [6] dan pada Tata Distro Pacitan [9]. Pengolahan data secara online ini dapat memperkecil peluang terjadinya kesalahan dan mempermudah dalam pembuatan laporan [10]. Admin pada toko ini dapat membuat laporan berdasarkan data pesanan yang masuk setiap harinya.

\section{Kesimpulan}

Berdasarkan hasil analisis, perancangan serta implementasi maka dapat diambil kesimpulan yaitu website pada Toko Shopsock dapat melakukan promosi dan memperluas pangsa pasarnya. Admin Toko Shopsock dapat melihat jumlah pembeli, rincian data pembeli, dan detail pemesanan yang dilakukan oleh pembeli. Website ini dapat dikembangkan dengan menambah fitur ulasan produk setelah membeli produk.

\section{Ucapan Terima Kasih}

Terimakasih kepada pemilik Toko Shopsock yang telah memberi waktu, tempat dan ijin untuk penelitian.

\section{DAFTAR PUSTAKA}

[1] Sasana Digital Consulting. 2020. Apa Itu Digitalisasi Serta Perannya di Dunia Bisnis dan Industri.https://sasanadigital.com/apa-itu-digitalisasi-serta-perannya-di-dunia-bisnis-dan-industri/

[2] Kosasi Sandy, 2014. Pembuatan Sistem Penjualan Berbasis Web Untuk Memperluas Pangsa Pasar. Prosiding SNATIF. Universitas Muria Kudus. https://jurnal.umk.ac.id/index.php/SNA/article/view/149 
[3] Ferdinandus Setu. 2021. Digitalisasi UMKM, Menteri Johnny: Pemerintah Tingkatkan Kapasitas dan Kemampuan Pelaku UMKM. https://kominfo.go.id/content/detail/35096/siaran-persno210hmkominfo062021-tentang-digitalisasi-umkm-menteri-johnny-pemerintah-tingkatkankapasitas-dan-kemampuan-pelaku-umkm/0/siaran_pers.

[4] F. Alfiah, R. Tarmizi, and A. A. Junidar. 2020. "Perancangan Sistem E-Commerce Untuk Penjualan Pakaian Pada Toko A\&S, Jurnal Sistem Informasi. . "ICIT J., vol. 6, no. 1, pp. https://www.neliti.com/publications/300387/perancangan-sistem-ecommerce-untuk-penjualanpakaian-pada-toko-as Hidayatullah, dan Kawistara, 2015. Pemrograman Web Bandung : Informatika

[5] SZ Linggar. 2020. Sistem Informasi Penjualan Sepatu Toko Angga Sport Berbasis Web. Repository. Program Studi Teknik Informatika. Fakultas Ilmu Komputer. Universitas Widya Dharma Klaten. http://repository.unwidha.ac.id/2221/1/Linggar\%20Fix.pdf

[6] Ricky Octa Pratama, Humisar Hasugian. 2019. Penerapan Metode E-Commerce Pada Toko Sepatu Kinya Store. Jurnal Idealis. Vol. 2 No. 3 Mei 2019. Fakultas Teknologi Informasi. Universitas Budi Luhur Jakarta. https://jom.fti.budiluhur.ac.id/index.php/IDEALIS/article/view/429/547

[7] Baldwin. 2020. 5 reasons why you need wishlists on your e-commerce website. https://www.baldwin.agency/blog/ecommerce/5-reasons-why-you-need-wishlists-on-your-ecommerce-website/

[8] Pressman Roger S. 2010. Rekayasa perangkat Lunak: Pendekatan Praktisi Edisi 7. Buku 1. Penerbit Andi: Yogyakarta

[9] Rulia Puji Hastanti, Bambang Eka Purnama, Indah Uly Wardati. 2015. Sistem Penjualan Berbasis Web (E-Commerce) Pada Tata Distro Kabupaten Pacitan. Bianglala Informatika. Vol 3 No. 2. Jurnal Komputer dan Informatika. Akademi Bina Sarana Informatika Yogyakarta

[10] Fauyhi Eko Nugroho. 2016. Perancangan Sistem Informasi Penjualan Online Studi Kasus Tokoku. Simetris. Vol 7 No. 2. Fakultas Teknik Universitas Muria Kudus. 